\title{
Selective Chemical Ionization of Nitrogen and Sulfur Heterocycles in Petroleum Fractions by Ion Trap Mass Spectrometry
}

\author{
C. S. Creaser*, F. Krokos, and K. E. O'Neill \\ School of Chemical Sciences, University of East Anglia, Norwich, United Kingdom
}

\author{
M. J. C. Smith and P. G. McDowell \\ BP Research, Sunbury-on-Thames, Middlesex, United Kingdom
}

\begin{abstract}
A procedure is reported for the selective ammonia chemical ionization of some nitrogen and sulfur heterocycles in petroleum fractions using ion trap mass spectrometry (ITMS). The ion trap scan routine is designed to optimize the population of ammonium reagent ions and eject from the trap (by radio frequency/direct current isolation) electron ionization products formed during reagent ion formation prior to ionization of the sample. The ITMS procedure is compared with standard ion trap detector and conventional quadrupole ammonia chemical ionization for the determination of nitrogen and sulfur heterocycles in gas oil and kerosine samples. Greatly enhanced selectivity is shown for the ITMS procedure by suppression of competing charge-exchange processes. ( $\mathrm{Am}$ Soc Mass Spectrom 1993, 4, 322-326)
\end{abstract}

$\mathrm{T}$ The removal of organic compounds containing nitrogen and sulfur is an important part of the petroleum-refining process [1]. Their presence in petroleum distillates results in the formation of environmental pollutants $\left(\mathrm{SO}_{x}, \mathrm{NO}_{x}\right)$ during combustion, and their reactivity can lead to catalyst poisoning in refinery processes. The presence of heterocyclic nitrogen compounds influences the storage stability of fuels. Alkyl indoles, in particular, have been linked to sediment formation in diesel fuels [2]. Analytical methods are required to identify the nitrogen and sulfur compounds in petroleum distillates so that the most efficient means may be devised for their removal.

Characterization of minor heteroatomic components of complex hydrocarbon mixtures is a demanding task (see, for example, ref 3 ). Chemical ionization (CI) provides a means of reducing the potential for interference from the hydrocarbon matrix; by careful choice of a reagent ion, selectivity may be achieved in the ionization of target compound types [4]; however, the CI reagent plasma formed in the ion source of a conventional mass spectrometer usually contains a variety of ions, and selectivity is limited by the occurrence of side reactions between the sample matrix and impurity ions in the plasma. In ammonia CI, one of the simpler reagent systems in this respect, the proton donor

\footnotetext{
* Present address and address for reprint requests: C. S. Creaser, Department of Chemistry \& Physics, Nottingham Trent University, Clifton Lane, Nottingham NG11 8NS, UK.
}

reagent ion $\mathrm{NH}_{4}^{+}$, is formed via the reactions [5]

$$
\begin{aligned}
\mathrm{NH}_{3} \stackrel{e^{-}}{\rightarrow} & \mathrm{NH}_{3}^{+} \\
\mathrm{NH}_{3}+\mathrm{NH}_{3}^{+} & \rightarrow \mathrm{NH}_{2}+\mathrm{NH}_{4}^{+}
\end{aligned}
$$

Whereas $\mathrm{NH}_{4}^{+}$is unreactive toward a wide range of hydrocarbons, the $\mathrm{NH}_{3}^{+}$ion (ionization potential of ammonia, $10.16 \mathrm{eV}$ [6]) undergoes charge-exchange reactions with aromatic hydrocarbons. Continuous production of $\mathrm{NH}_{3}^{++}$in the ion source of a conventional mass spectrometer, together with restrictions on the ammonia pressure, limits the selectivity achievable in ionization of basic nitrogen and sulfur compounds by prolon transfer from $\mathrm{NII}_{4}^{+}$.

It has been shown that ion-trapping devices (quadrupole ion trap and ion cyclotron resonance [ICR] mass spectrometers) can generate CI spectra free from contamination by ions formed by electron-impact ionization [7-9]. Furthermore, ion-trapping devices offer advantages over conventional instruments for highly selective $\mathrm{CI}$ because they operate efficiently in a pulsed mode, enabling a temporal separation of the reagent ion formation process and the $\mathrm{CI}$ reaction. Continuous production of unwanted ions can therefore be avoided. They also provide facilities for selective storage of ions [10] and enable purification of the reagent ion for subsequent, more selective ionization of target compounds [11].

By virtue of its high resolution and accurate mass measurement capabilities, Fourier transform ICR mass 
spectrometry (ICR/MS) provides a powerful means of identifying minor components of complex mixtures, particularly when combined with selective ionization methods [7]; however, the required instrumentation, which incorporates a superconducting magnet and fast signal-processing electronics, is costly. Quadrupole ion trap mass spectrometers, on the other hand, require comparatively simple instrumentation, and current instruments offer sensitivity advantages.

The present work was conducted to examine the selective ionization of nitrogen and sulfur compounds in petroleum distillates by ammonia CI. The performance of ion trap and conventional quadrupole mass spectrometry was compared. In particular, the capability of the low-resolution quadrupole ion trap instrument to characterize low levels of heteroatomics in complex hydrocarbon matrices was investigated.

\section{Experimental}

Ion trap CI experiments were carried out on a Finnigan-MAT (San Jose, CA) research quadrupole ion trap mass spectrometer, fitted with a Varian 3400 gas chromatograph operated using quadrupole ion trap mass spectrometry (ITMS) or standard ion trap detector (ITD) software. The helium pressure in the manifold was $1.5 \times 10^{-5}$ torr, and the ammonia reagent gas pressure was maintained at $2.8 \times 10^{-5}$ torr above the background pressure, measured at the vacuum housing ion gauge. Pyrrole (I, Figure 1, bottom) in toluene $(1+9)$ (high-performance liquid chromatography grade; Fisons, Loughborough, UK) was introduced via a liquid reservoir. Gas oil (light gas oil/light cycle oil from a UK refinery) and kerosine (from a Far East refinery) samples (diluted $1+9$ in toluene) were introduced by gas chromatography (GC) using a $50-\mathrm{m} \times$ $0.25-\mathrm{mm}$ inside-diameter (id) RSL-200 BP column (Alltech, UK). The GC conditions were as follows: injector temperature, $250^{\circ} \mathrm{C}$; transfer line, $240^{\circ} \mathrm{C} ; 1 \mu \mathrm{L}$ splitless injection (split flow at $20 \mathrm{mI}$, $/ \mathrm{min}$ ). The helium head pressure was $12 \mathrm{psi}$. The column oven temperature was $50{ }^{\circ} \mathrm{C}$ for $1 \mathrm{~min}$, raised to $100^{\circ} \mathrm{C}$ at $15^{\circ} \mathrm{C} / \mathrm{min}$, then to $250^{\circ} \mathrm{C}$ at $10^{\circ} \mathrm{C} / \mathrm{min}$, and held for $20 \mathrm{~min}$. Quadrupole CI mass spectrometry (CIMS) analyses were carried out on a VG Trio- 3 quadrupole mass spectrometer combined with a Hcwlctt-Packard (Avondale, PA) HP5890 gas chromatograph fitted with a $25-\mathrm{m} \times 0.22 \mathrm{~mm}$-id CPSil-5CB column (Chrompak, UK) using the same temperature program. ICR/MS experiments were conducted on a Nicolet Fourier transform mass spectrometry 2000 dual-cell instrument. Oil samples (between 2 and $10 \mathrm{mg}$ ) were introduced via a Brunfeldt all-glass heated inlet without separation. Internal standards (6-methyl quinoline; 2,6dimethylquinoline; 2-phenylquinoline; acridine; and $1,2,3,4,5,6,7,8$-octahydroacridine) were added for mass calibration and approximate quantification. The ammonia CI experimental sequence for the ICR/MS has been described previously [7].
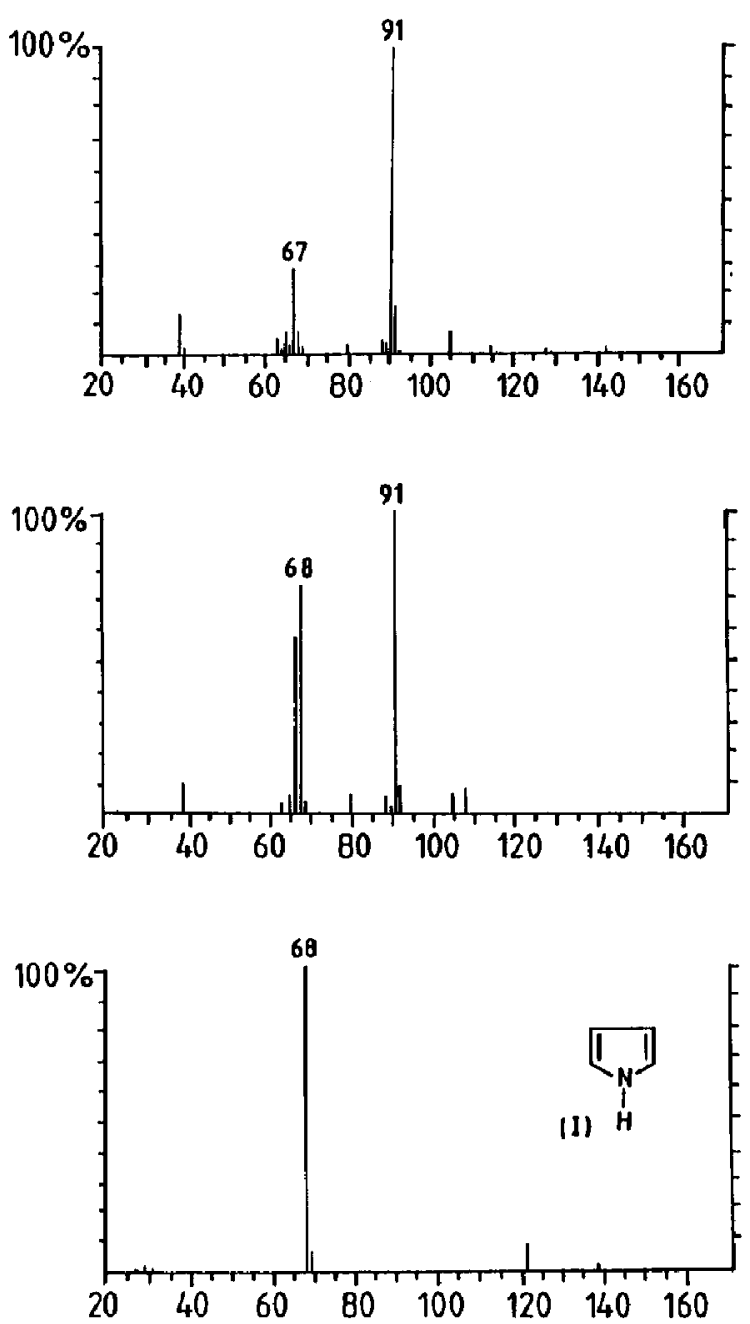

Figure 1. Mass spectra of pyrrole in toluene (top) EI spectrum, (middle) CI spectrum, and (bottom) $\mathrm{CI}$ spectrum using $\mathrm{rf} / \mathrm{dc}$ isolation of $\mathrm{NH}_{4}^{1}$.

\section{Results and Discussion}

The ion trap scan routine used for the selective $\mathrm{CI}$ of nitrogen and sulfur heterocycles is shown in Figure 2. The reagent ion-formation step in the ion trap ammonia $\mathrm{CI}$ was designed to create a large population of $\mathrm{NH}_{4}^{+}$reagent ions $(m / z 18)$ while minimizing the population of $\mathrm{NH}_{3}^{+}$ions $(\mathrm{m} / \mathrm{z} 17)$ and electron ionization (EI) products. These ions are formed during the initial ionization of ammonia and sample present in the trap. Ammonium ions are produced in part $\mathrm{B}$ of the scan routine (Figure 2) in which $\mathrm{NH}_{3}^{+-}$ions, formed from the reagent gas by EI, are held in the ion trap for a period of up to $120 \mathrm{~ms}$ to react with ammonia to give $\mathrm{NH}_{4}^{+}$(Eqs 1 and 2). To establish the optimum conditions for $\mathrm{NH}_{4}^{\prime}$ reagent ion formation, the abundances of $\mathrm{NH}_{3}^{+\cdot}$ and $\mathrm{NH}_{4}^{+}$were measured at various reagent- 


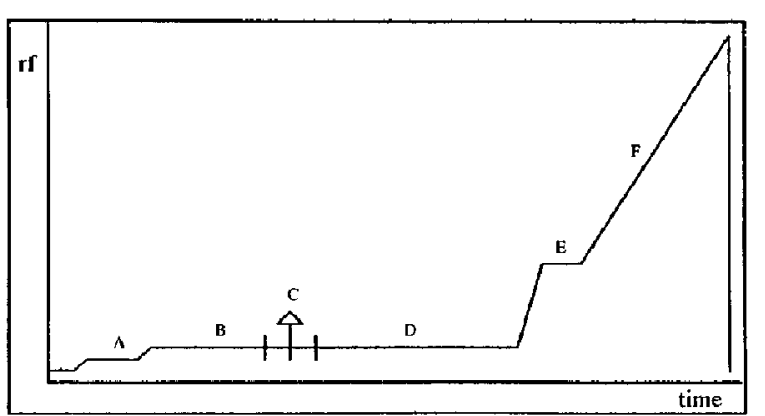

Figure 2. ITMS scan routine for the selective ammonia $C I$ of nitrogen and sulfur heterocycles (not to scale): $A$, ionization $(0.2 \mathrm{~ms}) ; \mathrm{B}_{r}$ formation of reagent ions $(20 \mathrm{~ms}) ; \mathrm{C}_{\text {s }}$ isolation of reagent ions with $\mathrm{dc}$ applied voltage $(-14 \mathrm{~V}$ for $1 \mathrm{~ms}) ; \mathrm{D}$, formation of sample ions (180 ms); E, selection of low-mass cutoff for start of acquisition (50 u); F, analytical scan (50-300 u).

Ammonium reagent ion formation

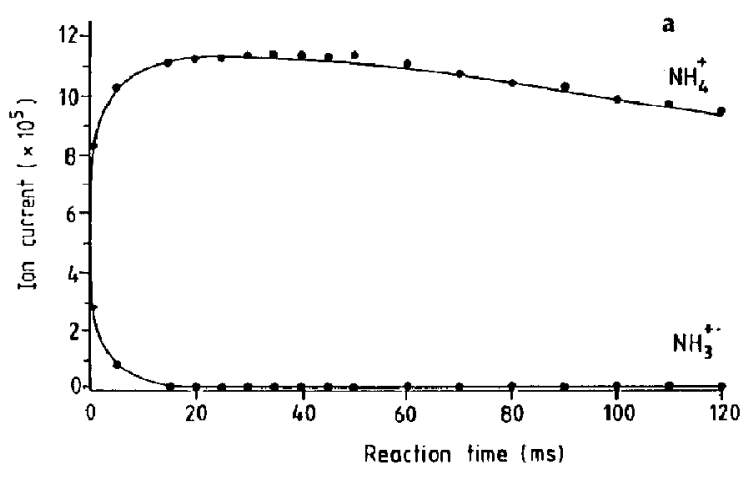

Pyrrale $(M+H)^{+}$ion formation by $\mathrm{NH}_{4}^{+}$

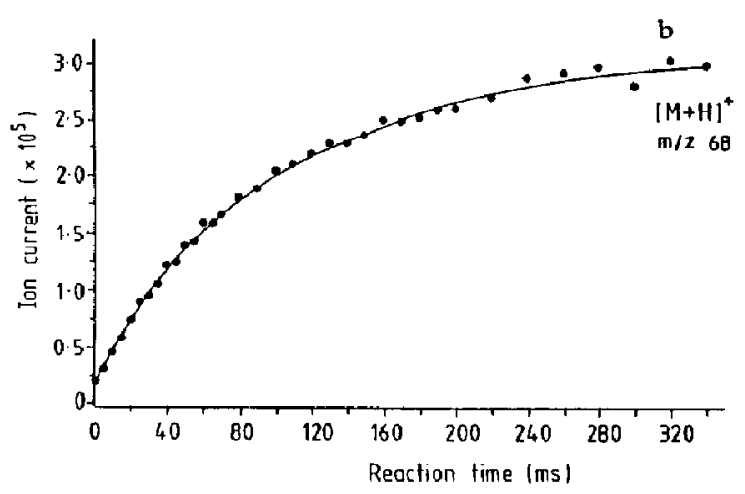

Figure 3. Variation of ion current with time during (a) ammonium reagent ion formation, (b) pyrrole $[\mathrm{M}+\mathrm{H}]^{+}$ion formation by $\mathrm{NH}_{4}^{+}$. reaction times, and the results for an ammonia partial pressure of $2.8 \times 10^{-5}$ torr are shown in Figure 3a. The abundance of $\mathrm{NH}_{3}^{+\cdot}(m / z 17)$ is initially high but rapidly decreases at longer reaction times as more $\mathrm{NH}_{4}^{+}$ions are formed. There is an optimum reaction time between 20 and $60 \mathrm{~ms}$, where the $\mathrm{NH}_{4}^{+}: \mathrm{NH}_{3}^{+}$ ratio is greater than 200:1. At longer reaction times, the $\mathrm{NH}_{4}^{+}$signal decreases because of space-charge effects and increased scattering. A reaction time of $20 \mathrm{~ms}$ was chosen for further studies.

Reagent ion formation is followed by reaction with sample molecules present in the trap (Figure 2, D) The effect of increasing the $\mathrm{CI}$ time for the reaction of $\mathrm{NH}_{4}^{+}$ with pyrrole (I) in a toluene matrix (diluted $1+9$ ) was observed by monitoring the $[\mathrm{M}+\mathrm{H}]^{+}(m / z 68)$ product ion abundance (Eq 3 ):

$$
\mathrm{NH}_{4}^{+}+\mathrm{C}_{4} \mathrm{H}_{5} \mathrm{~N}^{-} \mathrm{NH}_{3}+\left[\mathrm{C}_{4} \mathrm{H}_{6} \mathrm{~N}\right]^{+}
$$

As expected, the ion current for the $[\mathrm{M}+\mathrm{H}]^{+}$ion rises rapidly with increasing reaction time before leveling off as the reaction proceeds to completion (Figure $3 b$ ). During the initial EI period, EI products are formed from sample and matrix molecules present in the trap, and these remain during the $\mathrm{CI}$ of the pyrrole by reaction with $\mathrm{NH}_{4}^{+}$. This is illustrated by Figure 1 , where ions at $m / z 67$ and 91 are detected in addition
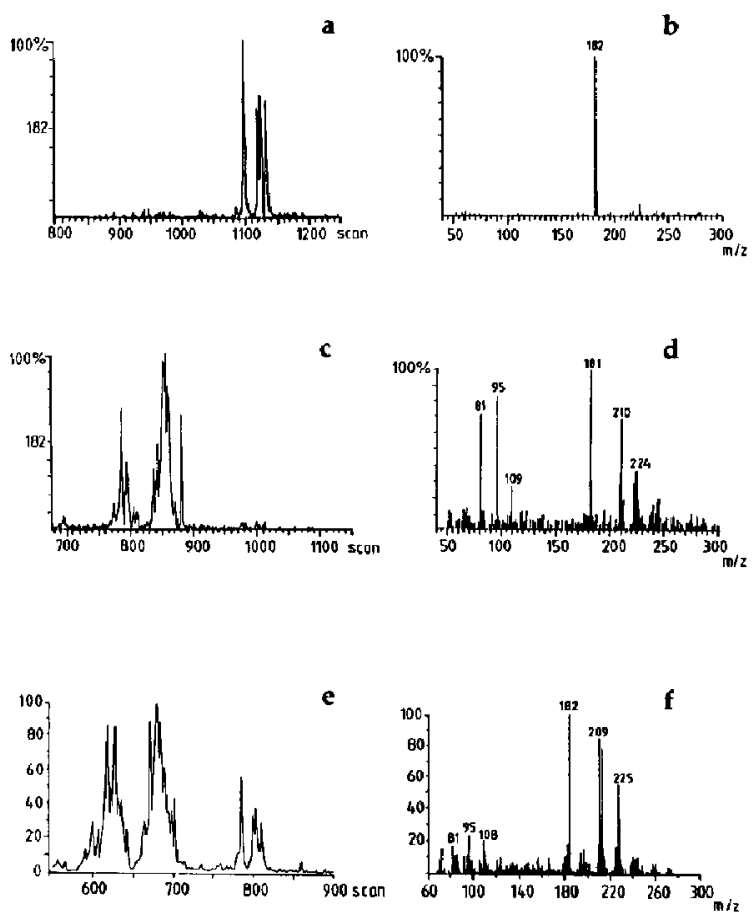

Figure 4. GC/CIMS analysis of a gas oil in toluene. Single-ion chromatogram of $m / z 182$ for (a) ITMS, (c) ITD, and (e) quadrupole. Mass spectra of 3-methylcarbazole peak (b) ITMS (scan 1123), (d) ITD (scan 1003), and (f) quadrupole (scan 803). 

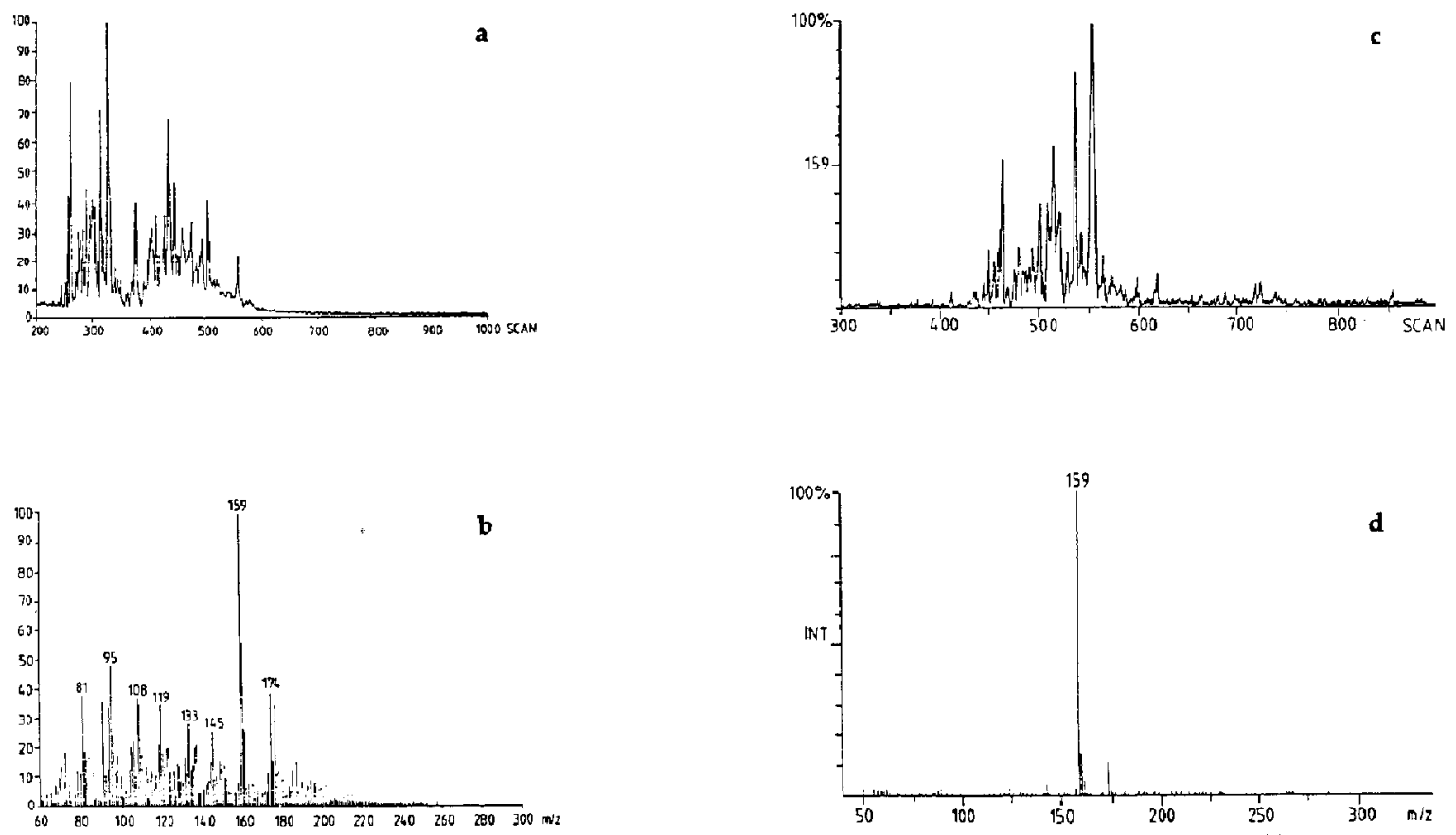

Figure 5. GC /CIMS analysis of kerosine in toluene. Single-ion chromatogram of $m / z 159$ for (a) quadrupole and (c) ITMS. Mass spectra obtained on (b) quadrupole (scan 434) and (d) ITMS (scan 552).

to the $[\mathrm{M}+\mathrm{H}]^{+}$ion of pyrrole (Figure 1, middle). These ions arise from EI of the pyrrole/toluene sample (Figure 1, top). The scan routine was therefore modified to include a radio frequency (rf)/direct current (dc) step $[10,11]$ to isolate the $\mathrm{NH}_{4}^{+}$(and residual $\mathrm{NH}_{3}^{+\cdot}$ ) by ejecting from the trap other $\mathrm{EI}$ or $\mathrm{CI}$ product ions formed during the ionization of the reagent gas, prior to the ionization of the sample by reaction with $\mathrm{NH}_{4}^{+}$. Under these conditions, proton transfer $\mathrm{CI}$ occurs with the $\mathrm{NH}_{4}^{+}$ion (eq 3), whereas the formation of charge-exchange products, by reaction of $\mathrm{NH}_{3}^{++}$with arnmatic components of the sample matrix, is minimized. Several classes of nitrogen heterocycles have been selectively ionized by GC/CIMS analysis using this procedure, including indoles, quinolines, carbazoles, and acridines. CI mass spectra of these compounds showed strong $[\mathrm{M}+\mathrm{H}]^{+}$ions and no fragment or adduct ions. The spectrum arising from the selective ionization of pyrrole in toluene is shown in Figure 1, bottom.

The ITMS CI routine was evaluated for the detection of carbazoles and other nitrogen heterocycles in samples of gas oil separated by capillary GC. An initial screen to identify the types of nitrogen compounds present in the gas oil was conducted by ICR/MS. Two significant series of nitrogen-containing peaks were identified and assigned on the basis of accurate mass measurements to protonated indoles $\left(\mathrm{C}_{n} \mathrm{H}_{2 n-9} n_{;} n=\right.$ 9-12) and carbazoles $\left(\mathrm{C}_{n} \mathrm{H}_{2 n-15} n_{;} n=12-15\right)$. Approximate quantification using the averaged response to the internal standards showed that members of each series were present at levels between 0.2 and 2.5 $\mu \mathrm{mol} / \mathrm{g}$. Members of the indole and carbazole series were selectively ionized in the gas oil sample by GC/CIMS using the ion trap scan routine. Figure 4a shows the single-ion chromatogram for the $[\mathrm{M}+\mathrm{H}]^{+}$ ion $(m / z 182)$ of methylcarbazole isomers eluting in the order 1-, 2-, 3-, and 4-methylcarbazole [3]. No peaks arising from the gas oil matrix are present in the chromatogram. The mass spectrum of 3-methylcarbazole (II) is shown in Figure $\mathbf{4 b}$, clearly demonstrating the absence of EI fragmentation and charge-exchange products. These results show significantly higher selectivity than those obtained by using either the standard ITD-type CI scan routine, which does not use an $\mathrm{rf} / \mathrm{dc}$ isolation step (Figure $4 \mathrm{c}$ and d) or by ammonia CI on a conventional quadrupole mass spectrometer (Figure $4 \mathrm{e}$ and $f$ ). In the latter case, charge-exchange and EI products of the aromatic hydrocarbons and other matrix components of the oil interfere extensively with the detection of the nitrogen heterocycles.<smiles>Cc1ccc2[nH]c3ccccc3c2c1</smiles>

(II)

A similar degree of selectivity is obtained using the CI ITMS scan routine for certain sulfur compounds 

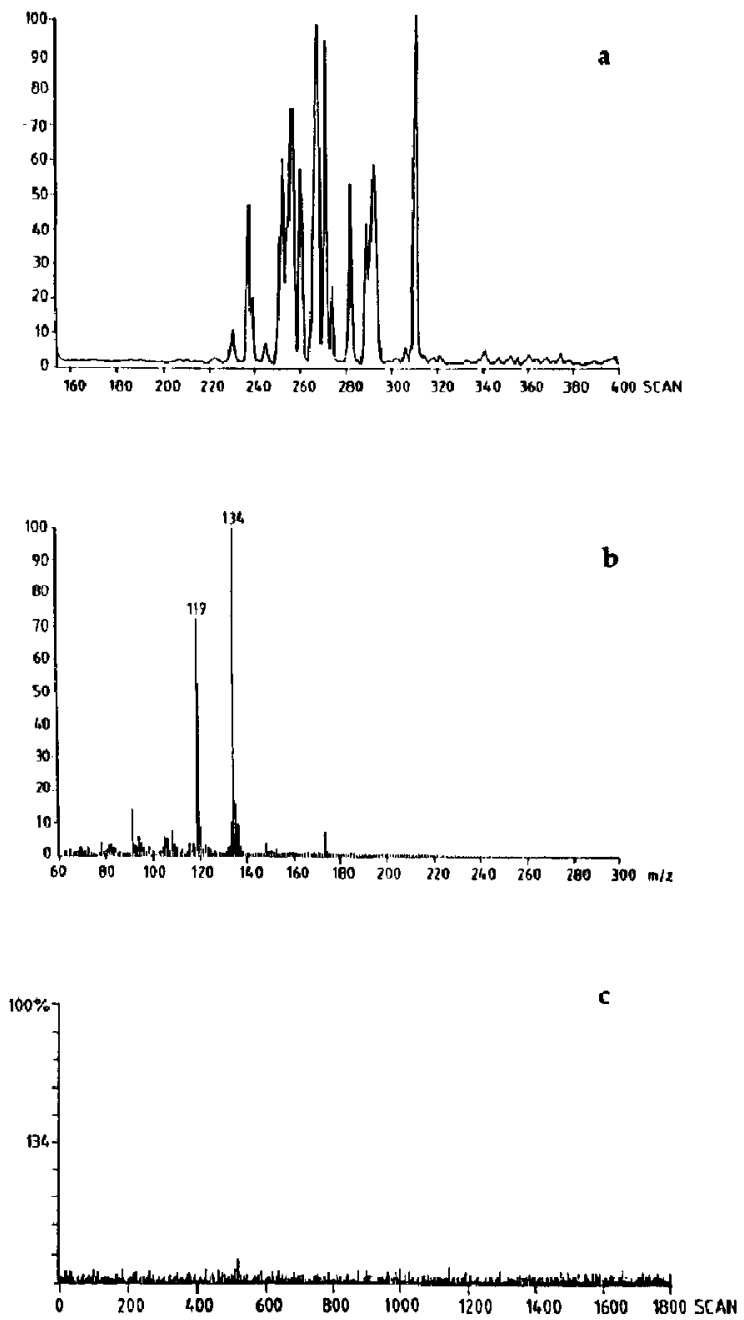

Figure 6. GC/CIMS analysis of kerosine in toluene. Single-ion chromatogram of $m / z 134$ for (a) quadrupole and (c) ITMS. (b) Mass spectrum obtained on quadrupole (scan 311$)$.

present in the kerosine sample. Ammonia CI ICR mass spectra recorded on the total kerosine sample show a major series of peaks assigned on the basis of accurate mass measurements to protonated molecular ions of monocyclic sulfides $\left(\mathrm{C}_{n} \mathrm{H}_{2 n} \mathrm{~S} ; n=7-13\right.$ ) (e.g., alkyl tetrahydrothiophenes / tetrahyd rothiopyrans). The series peaks at $m / z 159(n=9)$, and the abundance of the $\mathrm{C}_{9} \mathrm{H}_{18} \mathrm{~S}$ species was estimated at $3 \mu \mathrm{mol} / \mathrm{g}$. Comparison of the ITMS selected ion chromatogram $(\mathrm{m} / \mathrm{z}$ 159; Figure 5c) with that obtained using the quadrupole shows many more peaks in the quadrupole chromatogram (Figure 5a), and in all cases the quadrupole mass spectra are contaminated with charge-exchange product ions, indicating a lack of selectivity (Figure $5 \mathrm{~b})$. The mass spectrum of scan 552 obtained from the ion trap contains a strong $[\mathrm{M}+\mathrm{H}]^{+}$ion with minimal interference and is shown in Figure 5d without background subtraction. The higher quality of the ITMS spectrum has particular significance for the identification of sulfur compounds. The ${ }^{34} \mathrm{~S}$-isotope peak has the expected relative abundance (expected, $4.84 \%$; observed, $5.26 \%$ ) in the ITMS case, providing enhanced confidence in the assignment.

The major sources of interferences in the quadrupole spectra are charge-exchange products of alkyl benzenes that interfere with the detection of the nitrogen and sulfur heterocycles. For example, Figure 6a shows a single-ion chromatogram for the aromatic ions of formula $\mathrm{C}_{10} \mathrm{H}_{14}(\mathrm{~m} / \mathrm{z} 134)$ taken from the GC/CIMS analysis of the kerosine on the quadruple spectrometer. A typical alkyl benzene charge-exchange mass spectrum is shown in Figure 6b (scan 311). In contrast, charge-exchange products are absent from the singlcion chromatogram of $m / z 134$ form the GC/ITMS analysis of the kerosine (Figure 6c). This single-ion chromatogram was generated from the same data file as Figure $5 \mathrm{c}$. The absence of alkyl benzene peaks in the oil fractions investigated, although sulfur and nitrogen heterocycles may still be detected, confirms that proton transfer and not charge-exchange products are formed using the selective CI ITMS procedure.

I he llMS approach described here is highly effective in improving the quality of $\mathrm{CI}$ with the ammonia reagent. Major enhancements in selectivity are achieved for the ionization of nitrogen and sulfur compounds in hydrocarbon matrices in comparison to $\mathrm{CI}$ experiments performed with the standard ITD scan or with a conventional quadrupole mass spectrometer. The enhanced selectivity provides a means of characterizing indoles, carbazoles, and certain sulfur compounds at low levels in kerosines and light gas oils.

\section{Acknowledgments}

We acknowledge BP Research and the SERC (K. E. O'Neill) for their support of this work and permission to publish.

\section{References}

1. Reynolds, J. G. Chem. Ind. 1991, 570.

7. Pedley, J. F.; Hiley, R. W.; Hancock, R. A. Fuel 1988, 67, 1124.

3. Dzidic, I.; Balicki, M. D.; I.Iart, H. V. Fuel 1988, 67, 1155

4. Schubert, A. J.; Enke, C. G. Artal. Chim. Acta 1988, 211, 83.

5. Harrison, A. G. Chewrical Ionization Mass Spectrometry; CRC Press: Boca Raton, FL, 1983; p 64.

6. Lias, S. G.; Bartmess, J. E.; Liebman, J. F; Holmes, J. L.; Levin, R. D.; Mallard, W. G. J. Phys. Chem. Ref. Data 1988, 17, suppl. 1.

7. Smith, M. J. C. In Analytical Applications of Fourier Transform Ion Cyclotron Resonance Mass Spectrometry; Asamoto, B., Ed.; VCH Publishers: New York, 1991; pP 139-155.

8. Brodbelt, J. S.; Louris, J. N.; Cooks, R. G. Anal. Chem. 1987, $59,1278$.

9. Berberich, D. W.; Hail, M. E.; Johnson, J. V.; Yost, R. A. Int. J. Mass Spectrom. Ion Processes 1989, 94, 11.

10. Creaser, C. S.; Mitchell, D. S.; ONeill, K. E. Int. J. Mass Spectrom. Ion Processes 1991, 106, 21.

11. Strife, R. J.; Keller, P. R. Org. Mass Spectrom. 1989, 24, 201. 